\title{
Resposta do feijão-caupi à doses e formas de aplicação de fósforo em Latossolo Amarelo do Estado de Roraima
}

\author{
Armando José da SILVA ${ }^{1}$, Sandra Cátia Pereira UCHÔA², José Maria Arcanjo ALVES³ ${ }^{3}$ Antônio César Silva \\ LIMA $^{4}$, Célida Socorro Vieira dos SANTOS 5 , Jane Maria Franco de OLIVEIRA ${ }^{6}$, Valdinar Ferreira MELO ${ }^{7}$
}

\section{RESUMO}

A adubação fosfatada e as formas de aplicaçáo de fertilizantes fosfatados são fatores importantes no manejo das culturas. $\mathrm{O}$ objetivo do presente trabalho foi avaliar os efeitos de doses de fósforo e formas de aplicação de fertilizante fosfatado na cultura do feijão-caupi (Vigna unguiculata (L.) Walp) em solo de cerrado do Estado de Roraima. O experimento foi realizado em condiçóes de campo, em Latossolo Amarelo distrocoeso, no Campus do Cauamé da Universidade Federal de Roraima. O delineamento experimental foi o de parcelas subdivididas, com as parcelas principais organizadas em blocos casualizados, com três repetiçôes. As parcelas foram constituídas pelas formas de aplicação do fertilizante fosfatado: a) Lanço - L; b) Sulco simples - SS e c) Sulco duplo - SD. As subparcelas corresponderam às doses da adubaçáo fosfatada: $0 ; 0,5 ; 1,0 ; 1,5$ e 2,0 vezes a dose recomendada para adubaçáo de manutençáo do feijão-caupi. Houve efeito das doses de fósforo sobre o crescimento e absorção de fósforo pelas plantas. O maior crescimento, produção de vagem por planta, de grãos e absorção de fósforo ocorreu com a aplicação do fertilizante fosfatado aplicado em sulcos duplos.

PALAVRAS-CHAVE: Superfosfato simples, Absorção de fósforo, Cerrado.

\section{Response of cowpea (Vigna unguiculata (L.) Walp.) to phosphorus fertilization levels and application forms in Yellow Latosol of Roraima State/Brazil}

\begin{abstract}
Phosphorus fertilization and ways of phosphate fertilizers application are important factors considering crop management. This study aimed at assessing the effect of phosphorus rates and phosphate fertilizers application forms on growth and phosphorus uptake of cowpea plants cropped on cerrado soil in the State of Roraima, Brazil. An experiment took place under field conditions, on a Yellow Latosol, at Cauamé Campus of Roraima’s Federal University, located in the municipality of Boa Vista/ RR. The experimental design was split-plot, in a completely randomized blocks, with three replicates. The plots consisted of the following phosphoric fertilizers application forms: a) broadcasting; b) single furrow and c) double furrow. Sub-plots corresponded to phosphorus doses: $0,0,5 ; 1,0 ; 1,5$, and 2,0 times the recommended dose for cowpea maintenance fertilization $\left(60 \mathrm{~kg} \mathrm{ha}^{-1}\right.$ of $\left.\mathrm{P}_{2} \mathrm{O}_{5}\right)$. There was a significant effect of $\mathrm{P}$ rates over plant growth and plant uptake. Application of fertilizer in double furrows promoted higher plant growth, grain yield, and plant phosphorous uptake.
\end{abstract}

KEYWORDS: Single superphosphate, Phosphorus uptake, Cerrado.

\footnotetext{
1 Universidade Federal de Roraima. E-mail: armand@osite.com.br

2 Universidade Federal de Roraima. E-mail: scpuchoa@click21.com.br

${ }^{3}$ Universidade Federal de Roraima. E-mail: arcanjoalves@oi.com.br

${ }^{4}$ Universidade Federal de Roraima. E-mail: ant.cesar@uol.com.br

${ }^{5}$ Universidade Federal de Roraima. E-mail: celidasocorro@uol.com.br

${ }^{6}$ Embrapa Roraima. E-mail: jane@cpafrr.embrapa.br

${ }^{7}$ Universidade Federal de Roraima. E-mail: valdinar@yahoo.com.br
} 


\section{INTRODUÇÃO}

O feijāo-caupi (Vigna unguiculata (L.) Walp) é uma leguminosa comestível, dotada de alto conteúdo protéico, com boa capacidade de fixar nitrogênio e pouco exigente em fertilidade do solo. É cultivado predominantemente por pequenos produtores nas regióes Norte e Nordeste do Brasil.

Em solos tropicais, a prática da adubação fosfatada é imprescindível para a obtenção de produtividades adequadas pela maioria das culturas de interesse econômico (Sanchez e Salinas, 1981). Pesquisas realizadas por Silva et al. (1998), Alves et al. (2000) e Alves et al. (2001) revelaram alto potencial de resposta à adubação fosfatada nas culturas do arroz, feijãocaupi e algodáo em solos de cerrado do Estado de Roraima caracterizados pela baixa disponibilidade de fósforo.

Além da aplicação de adubos fosfatados, a forma como esses insumos são aplicados deve ser também considerada no manejo das culturas, uma vez que os solos tropicais geralmente apresentam elevado poder de adsorção de fosfatos. Segundo Novais et al. (1985), em função das elevadas taxas de adsorção de fósforo $(\mathrm{P})$, a aplicaçáo localizada deste nutriente pode ser mais vantajosa, principalmente em solos com baixos teores de P disponível.

Trabalhos realizados em solos da Amazônia apontam uma elevada variação na capacidade de adsorção de fósforo (Melo, 2002; Falcáo e Silva, 2004). De acordo com levantamento feito por Melo et al. (2004) a capacidade de fixaçấo de fósforo dos solos de cerrado em Roraima pode ser considerada baixa, embora tenham sido detectados valores elevados de adsorçấo de fósforo em pequenas manchas de Latossolo VermelhoAmarelo oxídico no nordeste do Estado.

Para Alves et al. (1999), a aplicaçáo localizada de P deve ser adotada com cautela, pois embora tenha a vantagem de reduzir temporariamente a sorção deste elemento pelo solo, contribui para a redução do volume de raízes. Há, de modo geral, maior crescimento de raízes, de modo particular de raízes mais finas, no local da aplicaçáo da fonte de $\mathrm{P}$, o que pode compensar, parcial ou totalmente, a baixa disponibilidade de P fora desse local (Barber, 1995). Este comportamento tem sido demonstrado em diversas culturas, tanto em trabalhos realizados sob condiçôes controladas (Castilhos e Anghinoni, 1988; Anghinoni, 1992), quanto em condições de campo (Vasconcelos et al., 1986; Prado et al., 2001; Bedin et al., 2003).

Objetivou-se com esse trabalho estudar o efeito de doses de fósforo e formas de aplicação de fertilizante fosfatado sobre os componentes de produção (altura da planta, número de vagens por planta e produção de grãos) e absorção de fósforo pelo feijão-caupi em um solo de cerrado do Estado de Roraima.

\section{MATERIAL E MÉTODOS}

O trabalho foi realizado em Latossolo Amarelo distrocoeso já incorporado ao processo produtivo com culturas anuais, localizado no Campus Cauamé do Centro de Ciências Agrárias da Universidade Federal de Roraima (UFRR), município de Boa Vista (2 49`11” N, longitude 60 40'24” W). Segundo a classificação de Köppen, o clima é do tipo Awi com duas estações climáticas bem definidas, uma chuvosa (abril-agosto) e outra seca (outubro-março) (Araújo et al., 2001).

$\mathrm{O}$ experimento foi realizado entre os meses de julho e setembro de 2002, correspondente ao final do período chuvoso. As análises químicas e físicas do solo foram realizadas, conforme Embrapa (1999) em amostra composta coletada trinta dias antes da data do plantio (Tabela 1).

Tabela 1 - Características químicas e físicas do solo utilizado no ensaio.

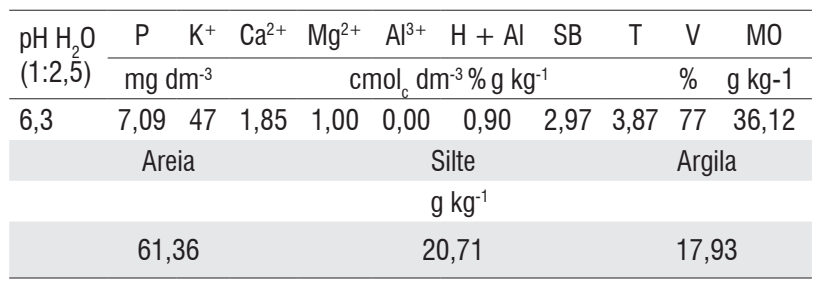

O delineamento experimental foi o de parcelas subdivididas, com as parcelas principais organizadas em blocos casualizados com três repetiçôes. As parcelas foram constituídas pelas formas de aplicação (FA) do fertilizante fosfatado (Lanço - L; Sulco Simples - SS e Sulco Duplo - SD), enquanto as subparcelas corresponderam às doses da adubação fosfatada: $0 ; 0,5 ; 1,0 ; 1,5$ e 2,0 vezes a dose recomendada para adubaçáo de manutenção: $60 \mathrm{~kg} \mathrm{ha}^{-1}$ de $\mathrm{P}_{2} \mathrm{O}_{5}$, perfazendo um total de 15 tratamentos e 45 unidades experimentais. Utilizou-se como fonte de $\mathrm{P}$ o superfosfato simples granulado com $20 \%$ de $\mathrm{P}_{2} \mathrm{O}_{5}$.

O preparo do solo constou de gradagem (grade de discos) até $25 \mathrm{~cm}$ de profundidade. Os sulcos de plantio e de adubação foram abertos manualmente utilizando-se enxadas em profundidades entre 10 e $15 \mathrm{~cm}$.

A adubação de plantio constou da aplicação de fósforo e potássio. A adubação fosfatada foi feita de acordo com os tratamentos anteriormente apresentados e a aplicaçáo de potássio foi feita com a utilização de $60 \mathrm{~kg} \mathrm{ha}^{-1}$ de $\mathrm{K}_{2} \mathrm{O}$ na forma de cloreto de potássio $\left(56 \%\right.$ de $\mathrm{K}_{2} \mathrm{O}$ ) a lanço. Dez dias após a emergência das plantas (DAE) procedeu-se a adubação de cobertura, a lanço, com $30 \mathrm{~kg} \mathrm{ha}^{-1}$ de N na forma de sulfato de amônio $(20 \%$ de N). Aos vinte DAE, foi feita aplicação de micronutrientes, via foliar, com as seguintes quantidades e fontes: cobre $-4 \mathrm{~kg} \mathrm{ha}^{-1}-\mathrm{CuSO}_{4} \cdot 5 \mathrm{H}_{2} \mathrm{O}$; zinco $-2 \mathrm{~kg} \mathrm{ha}^{-1}$ - $\mathrm{ZnSO}_{4} \cdot 7 \mathrm{H}_{2} \mathrm{O}$; boro $-1 \mathrm{~kg} \mathrm{ha}^{-1}-\mathrm{H}_{3} \mathrm{BO}_{3}$; molibdênio - 0,4 $\mathrm{kg} \mathrm{ha}{ }^{-1}-\mathrm{Na}_{2} \mathrm{MoO}_{4} \cdot 2 \mathrm{H}_{2} \mathrm{O}$. 
A aplicação do fertilizante fosfatado constou dos seguintes tratamentos: (a) A lanço (L) - aplicação manual em toda área da parcela; (b) Sulcos simples (SS) - aplicação manual concentrada ao longo do sulco de plantio, abaixo da semente e (c) Sulcos duplos (SD) - consistiu de dois sulcos abertos manualmente, ficando o sulco de plantio posicionado entre os dois sulcos da aplicação do fertilizante fosfatado a $10 \mathrm{~cm}$, de modo que a faixa fertilizada passou a ser o dobro da anterior.

Foi utilizada a cultivar de feijão-caupi "Pretinho Precoce 1", originária de segregaçôes ocorridas dentro da linhagem IT 85D3428-4, de porte semi-ereto, pedúnculo floral longo, com as vagens acima da folhagem, e cor do tegumento do grão preta (Alves $e t$ al., 2001). O plantio foi realizado em espaçamento entre linhas de $0,5 \mathrm{~m}$, com uma densidade de 15 sementes por metro linear. Dez dias após a emergência, foi realizado o desbaste, deixando-se oito plantas.

Por ocasiáo do pleno florescimento (35 dias após a emergência - DAE) fez-se a coleta de 20 folhas trifolioladas por tratamento para a determinaçáo do teor foliar de P. A amostragem foi feita no terço mediano das plantas da área útil das parcelas e subparcelas. As amostras foram acondicionadas em sacos de papel, secas em estufa de circulaçáo forçada de ar a $65^{\circ} \mathrm{C}$, pesadas e moídas. A determinação do $P$ foi feita após digestão nitro-perclórica do tecido vegetal (Tedesco, 1985).

Aos 50 DAE procedeu-se a medição da altura das plantas e contagem do número de vagens maduras por planta. Essas determinaçóes foram efetuadas em oito plantas representativas da fileira central de cada parcela. A produção de grãos foi determinada aos 55 DAE em uma única colheita, coletando-se as vagens das duas fileiras centrais de cada parcela, deixando-se $0,5 \mathrm{~m}$ de bordadura nas extremidades da parcela.

Os dados foram submetidos a análise de variância, teste $\mathrm{F}$ e regressão, utilizando-se programas do Sistema para Análises Estatísticas e Genéticas (SAEG), de acordo com modelo descrito em Gomes (1990).

\section{RESULTADOS E DISCUSSÃO}

Houve efeito significativo das formas de aplicação do fertilizante fosfatado e das doses de $\mathrm{P}$ sobre todas as características de crescimento, produção de grãos e concentração de fósforo no tecido foliar. A interação entre as doses de $\mathrm{P}$ e as formas de aplicaçáo do fertilizante fosfatado foi significativa para a maioria das variáveis avaliadas, evidenciando um comportamento diferenciado das doses de $\mathrm{P}$ dentro de cada forma de aplicaçấo estudada (Tabela 2).

A aplicaçáo do fertilizante fosfatado em sulco duplo foi superior à aplicaçăo em sulco simples e a lanço (Tabela 3). De modo geral, estes resultados estáo em concordância com os trabalhos de Prado etal.(2001) eBarreto eFernandes (2002) realizados com a cultura do milho em solos do triângulo mineiro e de tabuleiro costeiro da Bahia, respectivamente.
Tabela 2 - Resumo da análise de variância relativa aos componentes de produção de feijão-caupi e teor foliar de $\mathrm{P}$

\begin{tabular}{|c|c|c|c|c|c|}
\hline \multirow[b]{2}{*}{$\begin{array}{l}\text { Causa de } \\
\text { Variação }\end{array}$} & \multirow[b]{2}{*}{$\mathrm{GL}$} & \multicolumn{4}{|c|}{ Quadrado Médio } \\
\hline & & $\begin{array}{c}\text { Altura da } \\
\text { planta }\end{array}$ & $\begin{array}{c}\mathrm{N}^{0} \mathrm{de} \\
\text { vagem } \\
\text { por planta }\end{array}$ & $\begin{array}{c}\text { Produção de } \\
\text { grãos }\end{array}$ & $\begin{array}{l}\text { Teor foliar } \\
\text { de fósforo }\end{array}$ \\
\hline Blocos & 2 & $46,34^{\star \star}$ & $2,16 \mathrm{~ns}$ & $7.013,85 \mathrm{~ns}$ & $0,02 \mathrm{~ns}$ \\
\hline $\begin{array}{l}\text { Formas de } \\
\text { Aplicação (FA) }\end{array}$ & 2 & $10,88^{* *}$ & $13,40 * \star$ & $125.896,65^{\star \star}$ & 0,34 ** \\
\hline Resíduo (a) & 4 & 1,11 & 1,84 & $2,056,48$ & 0,06 \\
\hline $\begin{array}{l}\text { Doses de } \\
\text { Fósforo (DP) }\end{array}$ & 4 & $287,54^{* \star}$ & $14,40 * *$ & $142.255,08^{* *}$ & $14,98 * *$ \\
\hline $\mathrm{FA} \times \mathrm{DP}$ & 8 & $13,45^{\star \star}$ & $0,19 \mathrm{~ns}$ & $22.481,97^{\star \star}$ & $0,24^{\star \star}$ \\
\hline DP dentro de $L$ & 4 & $72,62^{\star \star}$ & - & $194.244,00 * *$ & $1,46^{\star \star}$ \\
\hline DP dentro de SS & 4 & $122,77^{* *}$ & - & $107.972,84^{* *}$ & $0,98 * *$ \\
\hline $\begin{array}{l}\text { DP dentro de } \\
\text { SD }\end{array}$ & 4 & $133,24^{* *}$ & - & $468.907,87^{\star \star *}$ & $1,85^{\star \star}$ \\
\hline Resíduo (b) & 24 & 5,03 & 1,13 & $2.113,38$ & 0,07 \\
\hline CV (a) (\%) & & 9,7 & 15,53 & 5,22 & 8,6 \\
\hline CV (b) (\%) & & 8,9 & 12,16 & 5,21 & 9,3 \\
\hline
\end{tabular}

$\mathrm{L}=$ Aplicação de $\mathrm{P}$ a lanço; $\mathrm{SS}=$ Aplicação de $\mathrm{P}$ em sulcos simples; $\mathrm{SD}=$ Aplicação de P em sulcos duplos.

$\star \star$ - Significativo a $1 \%$ de probabilidade.

ns - Não significativo

Tabela 3 - Valores médios de variáveis de crescimento e produção de feijãocaupi cultivado sob diferentes formas de aplicação de fertilizante fosfatado

\begin{tabular}{lccc}
\hline $\begin{array}{l}\text { Formas de } \\
\text { Aplicação }\end{array}$ & Altura (cm) & $\begin{array}{c}\mathrm{N}^{0} \text { de Vagens } \\
\text { Planta }^{-1}\end{array}$ & $\begin{array}{c}\text { Teor foliar de P } \\
\left(\mathrm{g} \mathrm{kg}^{-1}\right)\end{array}$ \\
\hline Lanço & $53,2 \mathrm{~b}$ & $8,32 \mathrm{~b}$ & $2,1 \mathrm{~b}$ \\
Sulco Simples & $53,1 \mathrm{~b}$ & $8,07 \mathrm{~b}$ & $2,2 \mathrm{~b}$ \\
Sulco Duplo & $54,9 \mathrm{a}$ & $9,82 \mathrm{a}$ & $3,1 \mathrm{a}$ \\
\hline
\end{tabular}

Nas colunas, valores seguidos por letras iguais não diferem estatisticamente entre si pelo teste de Tukey $(p<0,05)$.

O efeito favorável da aplicação de fósforo em sulcos duplos no crescimento das plantas também foi observado por Prado et al. (2001). Esses autores concluíram que houve aumento da produçáo de grãos e absorção de $\mathrm{P}$ pela cultura do milho em Latossolo Vermelho-Escuro distrófico. A aplicação localizada do adubo fosfatado nos dois lados da linha promoveu maior desenvolvimento radicular na área adubada, contribuindo para um maior crescimento das plantas e maior produção de grãos, o que também pode ter ocorrido com as plantas de feijão no presente estudo. Segundo Barber (1995), ocorre uma maior proliferação de raízes em zonas adubadas do solo, mas esse fenômeno depende da quantidade de fósforo aplicada.

Além de promover maior absorção do fósforo, a aplicação de $\mathrm{P}$ em sulcos duplos pode proporcionar também um melhor aproveitamento deste elemento pela planta. Nessa linha de raciocínio, trabalho realizado por Anghinoni e Barber (1980) apontou estresse nutricional em plantas de milho quando apenas parte do sistema radicular estava suprido de fósforo. Novais et al. (1985) também observaram, que o P se acumula de forma irregular nas folhas de milho em conseqüência de sua disponibilidade limitada a apenas uma parte do sistema 
radicular. Quando o P é fornecido nos dois lados da planta, a distribuição de $\mathrm{P}$ interna é uniformemente favorecida (Prado et al., 2001).

Estudos de regressão relativos ao efeito das doses de P na produção de grãos de feijão-caupi para cada forma de aplicação evidenciaram a resposta das plantas às doses aplicadas, o que está de acordo com diversos trabalhos realizados com outras culturas e outras condiçóes edafoclimáticas (Souza et al., 1998; Barreto e Fernandes, 2002; Bedin et al., 2003)

É interessante observar que, independentemente da forma como o fertilizante foi aplicado, a dose recomendada de $\mathrm{P}\left(60 \mathrm{~kg} \mathrm{ha}^{-1}\right.$ de $\mathrm{P}_{2} \mathrm{O}_{5}$ ) para a cultura do feijão-caupi, considerando o teor de $\mathrm{P}$ disponível no solo, náo foi suficiente para proporcionar as maiores produçóes (Figura 1). O efeito da aplicação em sulco duplo foi menor nas menores doses de $\mathrm{P}$, mas superior às outras formas de aplicação, o que também foi observado na cultura do milho por Prado et al. (2001). Observou-se ainda que, quando o fertilizante foi aplicado a lanço e em sulco duplo, as produtividades máximas foram obtidas com o uso de aproximadamente $90 \mathrm{~kg}$ de $\mathrm{P}_{2} \mathrm{O}_{5}$ por hectare.

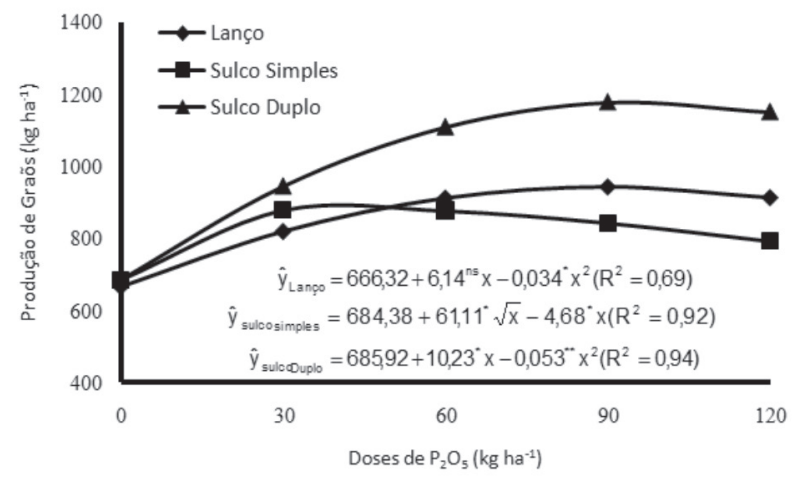

Figura 1 - Efeito de doses de fósforo sobre a produção de grãos de feijão-caupi cultivado sob diferentes formas de aplicação de fertilizante fosfatado.

A localização do fertilizante no sulco simples afetou negativamente o desempenho produtivo das plantas de feijãocaupi, pois a partir da dose de $57 \mathrm{~kg} \mathrm{ha}^{-1}$ de $\mathrm{P}_{2} \mathrm{O}_{5}$ a produçáo de grãos apresentou incrementos decrescentes. Isso porque a localização de $\mathrm{P}$ de uma fonte solúvel pode, também, ser crítica para a absorção de outros nutrientes, como o N (Novais e Smith, 1999).

De acordo com as equaçóes de regressão estimadas, a produtividade máxima de feijão-caupi seria de $1.177,32 \mathrm{~kg}$ $\mathrm{ha}^{-1}$ e 943,52 $\mathrm{kg} \mathrm{ha}^{-1}$ para a aplicação de $90 \mathrm{~kg} \mathrm{ha}^{-1}$ de $\mathrm{P}_{2} \mathrm{O}_{5}$ em sulcos duplos e a lanço, respectivamente (Figura 1). Nesse sentido, pode-se inferir que as estimativas de incrementos da produção com a adubação fosfatada podem ser aumentadas em aproximadamente $20 \%$ com a aplicação do fertilizante fosfatado em sulcos duplos em relaçáo à aplicação convencional e a lanço em cultivos de campo. Isto indica a maior eficiência desse manejo em termos de aumento de produtividade, o que resulta em reduçóes expressivas nos custos com a utilizaçáo de adubos fosfatados na cultura do feijâo-caupi.

Os teores foliares de $\mathrm{P}$ foram significativamente influenciados pelas doses nas três formas de aplicação do adubo (Figura 2). A exemplo do que ocorreu para produção de grãos, a forma de localização em sulcos duplos também foi superior no incremento dos teores foliares de $\mathrm{P}$ nas plantas. Os maiores teores de $\mathrm{P}$ nas folhas foram obtidos com a aplicaçáo de 90 $\mathrm{kg} \mathrm{ha}^{-1}$ de $\mathrm{P}_{2} \mathrm{O}_{5}$ no sulco duplo, dose superior à recomendada para adubação de manutenção do feijão-caupi em solos de cerrado de Roraima. Esses teores encontram-se dentro da faixa

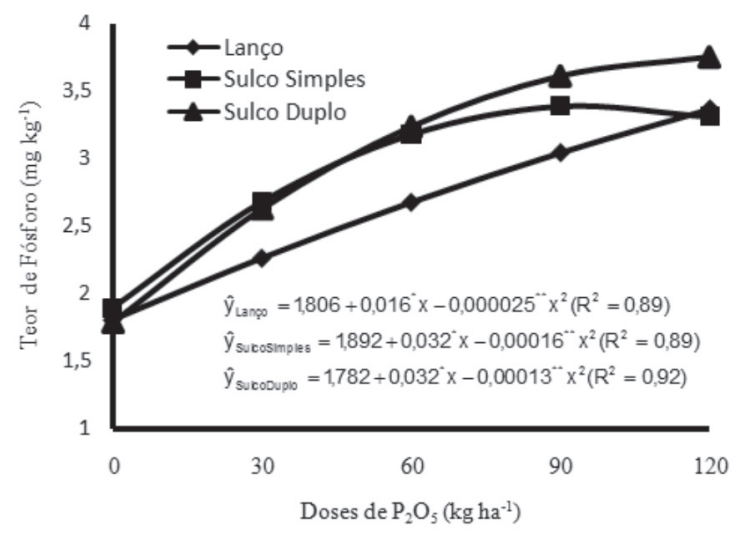

Figura 2 - Efeito de doses de fósforo sobre a concentração de P em folhas de feijão-caupi cultivado sob diferentes formas de aplicação de fertilizante fosfatado.

considerada adequada pela literatura para o feijão-caupi, que é de 2,6 a 5,0 $\mathrm{mg} \mathrm{kg}^{-1}$ (Malavolta, et al., 1989).

O aumento do teor foliar de P com aplicação da adubaçáo fosfatada localizada em sulcos duplos pode explicar o aumento da produção de grãos observado também nessa condição, considerando-se que há relatos na literatura a respeito da estreita correlação entre teores foliares de nutrientes e produtividade das culturas (Stryker et al., 1974; Neptune et al., 1982).

\section{CONCLUSÕES}

1 - A aplicação do fertilizante fosfatado em sulco duplo proporcionou maior crescimento, produção de grãos e absorção de fósforo pelas plantas, não havendo diferença entre a aplicação a lanço e em sulco simples.

2 - A dose de $90 \mathrm{~kg} \mathrm{ha}^{-1}$ de $\mathrm{P}_{2} \mathrm{O}_{5}$ proporcionou maior produtividade de grãos de feijâo-caupi e aumentou a concentraçáo de fósforo nas folhas quando aplicada em sulco duplo; 


\section{BIBLIOGRAFIA CITADA}

Alves, J.M.A.; Albuquerque, J. de A.A.; Uchôa, S.C.P.; Silva, A.J. da, Silva, L.C. da; Santos, E.G. dos. 2001. Componentes de produção de uma linhagem de feijão-caupi precoce consorciada com a mandioca no Lavrado de Roraima, p. 98-101. In: V Reunião Nacional de Pesquisa de Caupi. Teresina - PI.

Alves, J.M.A.; Silva, A.J. da; Uchôa, S.C.P.; Oliveira, J.M.F. de; Silva, L.C. da. 2000. Resposta da cultivar de algodão Antares a níveis de adubação fosfatada e calagem em Latossolo Amarelo da formaçáo Boa Vista do Estado de Roraima. In: XXIV Reunião Brasileira de Fertilidade do Solo e Nutrição de Plantas, Santa Maria, Sociedade Brasileira de Ciência do Solo.

Alves, V.M.C.; Magalhães, J.V.; Vasconcelos, C.A.; Novais, R.F.; Bahia Filho, A.F.C.; França, G.E.; Oliveira, C.A.; França, C.C.M. 1999. Acúmulo de nitrogênio e de fósforo em plantas de milho afetadas pelo suprimento parcial de fósforo às raízes. Revista Brasileira de Ciência do Solo, 23: 299-305.

Anghinoni, I. 1992. Uso do fósforo pelo milho afetado pela fração de solo fertilizada com fosfato solúvel. Revista Brasileira de Ciência do Solo, 16: 349-353.

Anghinoni, I.; Barber, S.A. 1980. Phosphorus influx and growth characteristics of corn roots as influenced by phosphorus supply. Agronomy Journal, 22: 685-688.

Barber, S.A. 1995. Mecanismos de absorção de fósforo sob condiçôes de estresse ambiental, p. 233-237. In: Simpósio Internacional sobre Estresse Ambiental. 1, Belo Horizonte. Anais, Sete Lagoas, Empresa Brasileira de Pesquisa Agropecuária.

Barreto, A.C.; Fernandes, M.F. 2002. Produtividade e absorção de fósforo por plantas de milho em função de doses e modos de aplicação de adubo fosfatado em solo de tabuleiro costeiro. Revista Brasileira de Ciência do Solo, 26: 151-156.

Bedin, I.; Furtini Neto, A.E.; Resende, A.V.; Faquim, V.; Tokura, A.M.; Santos, J.Z.L. 2003. Fertilizantes fosfatados e produção da soja em solos com diferentes capacidades tampão de fosfato. Revista Brasileira de Ciência do Solo, 27: 639-646.

Castilhos, D.D.; Anghinoni, I. 1988. Influência do suprimento de fósforo a diferentes fraçóes do sistema radicular sobre o comportamento do milho. Revista Brasileira de Ciência do Solo, 12: 263-267.

EMBRAPA. 1999. Manual de análises químicas de solos, plantas e fertilizantes. Embrapa, Brasília, 370 pp.

EMBRAPA/BNDES. 1998. Estudo sobre a viabilidade agrícola dos cerrados de Roraima. Boa Vista, Embrapa-Roraima. 104 pp.

Falcão, N.P. de S.; Silva, J. R. A. de. 2004. Características de adsorção de fósforo em alguns solos da Amazônia Central. Acta Amazonica, 34:337-342.

Gomes, F.P. 1990. Curso de estatística experimental. São Paulo, Nobel. 467 pp.

Malavolta, E.; Vitti, G.C.; Oliveira, S.A. de. 1989. Avaliação do estado nutricional das plantas: princípios e aplicaçôes. Piracicaba, Associaçáo Brasileira para Pesquisa da Potassa e do Fosfato. $201 \mathrm{pp}$
Melo, V.F. 2002. Solos e indicadores de uso agrícola em Roraima: área indígena Maloca do Flechal e de colonizaçáo do Apiaú. Tese de Doutorado, Universidade Federal de Viçosa, Viçosa, $145 \mathrm{pp}$.

Melo, V.F.; Gianluppi, D.; Uchôa, S.C.P. 2004. Características edafológicas dos solos do Estado de Roraima. Universidade Federal de Roraima, DSI, Boa Vista. 46 pp.

Neptune, A.M.L.; Nakagawa, J.; Scotton, L.C.; Souza, E.A. 1982. Efeitos de doses não eqüidistantes de $\mathrm{N}, \mathrm{P}, \mathrm{K}$, nas concentraçóes desstes macronutdrientes na folha e na produção de milho (Zea mays L.). Anais da Escola Superior de Agricultura "Luiz de Queiroz", 39: 917-941.

Novais, R.F.; Ferreira, R.P.; Neves, J.C.L.; Barros, N.F. 1985. Absorção de fósforo e crescimento do milho com sistema radicular parcialmente exposto à fonte de fósforo. Pesquisa Agropecuária Brasileira, 20: 749-754.

Novais, R.F.; Smith, T.J. 1999. Fósforo em solo e planta em condiçöes tropicais. Universidade Federal de Viçosa, Viçosa. 399 pp.

Prado, R.M.; Fernandes, F.M.; Roque, C.G. 2001. Resposta da cultura do milho a modos de aplicaçáo e doses de fósforo, em adubação de manutenção. Revista Brasileira de Ciência do Solo, 25: 83-90.

Sanchez, P.A.; Salinas, J.G. 1981. Low input Technology of managing oxisols and ultisols in tropical América. Adv. Agron., 24: $280-406$.

Silva, A.J. da; Melo, V.F.; Medeiros, R.D. de. 1998. Limitaçóes nutricionais para a cultura do arroz em solo de várzea do estado de Roraima. II. Concentração de macronutrientes na parte aérea. In: XXIII REUNIĀO BRASILEIRA DE FERTILIDADE DO SOLO E NUTRIÇÃO DE PLANTAS, Caxambu. Resumos. Caxambu, MG, Universidade Federal de Lavras, Sociedade Brasileira de Ciência do Solo.

Souza, E.C.A.; Coutinho, E.L.M.; Natale, W.; Barbosa, J.C. 1998. Respostas do milho à adubaçáo com fósforo e zinco. Pesquisa Agropecuária Brasileira, 33: 1031-1036.

Stryker, R.B.; Gilliam, J.W.; Jackson, W.A. 1974. Nonuniform transport of phosphorus from single roots to the leaves of Zea mays. Plant Physiology Physiol, 30: 231-239.

Tedesco, M.J. 1985. Análise de solo, plantas e outros materiais. Universidade Federal do Rio Grande do Sul, Porto Alegre. Boletim Técnico de Solo 5. 188 pp.

Vasconcellos, C.A.; Santos, H.L.; França, G.E.; Bahia Filho, A.F.C.; Pitta, G.V.E. 1986. Doses, modos de aplicação e fontes de fosfatos na produção de milho. Pesquisa Agropecuária Brasileira, 21: 245-254.

Recebido em 23/11/2007

Aceito em 30/10/2009 
